\title{
Asset Mapping as a Tool for Identifying Resources in Community Health: A Methodological Overview
}

\author{
Maaz Shahid ${ }^{1,2}$, Marcus Vaska ${ }^{3}$, and Tanvir C Turin ${ }^{1,4,5, *}$ \\ ${ }^{1}$ Department of Family Medicine, Cumming School of Medicine, University of Calgary, Calgary, AB, \\ Canada \\ ${ }^{2}$ Department of Epidemiology, Biostatistics and Occupational Health, McGill University, Montreal, \\ Quebec, Canada. \\ ${ }^{3}$ Knowledge Resource Service, Tom Baker Cancer Centre, Alberta Health Services, Calgary, AB, \\ Canada. \\ ${ }^{4}$ Department of Community Health Sciences, Cumming School of Medicine, University of Calgary, \\ Calgary, AB, Canada \\ ${ }^{5} \mathrm{O}$ 'Brien Institute for Public Health, University of Calgary, Calgary, $\mathrm{AB}$, Canada \\ "Corrresponding author: turin.chowdhury@ucalgary.ca
}

Received: May 2, 2018; revised: Oct 27, 2018; accepted: Jan 27, 2019.

\begin{abstract}
By focusing on a community's strengths instead of its weaknesses, the process of asset mapping provides researchers with a new way to assess community health. This process is also a useful tool for assessing health-related needs, disparities, and inequities within the communities. This paper aims to serve as a basic and surface level guide to understanding, planning, and creating an asset map. A step-by-step guideline is provided in this paper as an introduction to those interested in creating an asset map using organizational outlines and previous application in research projects. To help readers better grasp asset maps, a few examples are first provided that show the application of asset maps in health research, community engagement, and community partnerships. This is followed by elaboration of the six steps involved in the creation of an asset map. This paper introduces researchers to the steps required to create an asset map, with examples from the published literature. The intended audience includes students and researchers new to the creation of asset maps.
\end{abstract}

Keywords: Asset mapping, resource identification, community health. 


\section{Introduction}

When it comes to assessing a community, the traditional model is based on a needs-driven approach: 'What is missing from this community?' Although it made sense intuitively, its weakness was that it focused on the deficiencies of communities, which can lead to a cycle of dependence on external aid (McKnight and Kretzmann, 1993). A model that instead focuses on strengths in the form of assets was introduced by Kretzmann \& McKnight in 1993 (McKnight and Kretzmann, 1993). They presented the concept that assets are resources that a community has, which can help address an issue at hand. Although the list of what can constitute an "asset" has greatly increased, the classical categories (McKnight, J, 2017) of possible assets include: individuals [e.g. health professionals], local associations [e.g. neighbourhood association, community organizations], neighborhood institutions [e.g. public library, primary care clinics, pharmacies], physical assets [e.g. park, gymnasium], stories [e.g. urban legends], and exchange between neighbours/local economy [e.g. garage sales/farmer's market, peer support group activities]. The asset mapping process gives the researchers, policy makers, or community workers a good understanding of what is or what is not available in dealing with an issue of interest and sets up for informed evidence-based planning.

\subsection{Usefulness of an Asset Map}

Asset mapping, in general, refers to the comprehensive compilation of a list of assets and the further optional step of then locating and listing the assets on a map. As noted in both Smith et al, 2017 \& Lightfoot et al, 2014 (Lightfoot et al., 2014; Smith et al., 2017), an asset map can a "useful tool for assessing health-related needs, disparities, and inequities within communities." Just as the World Health Organization (WHO, 2018) shifted their definition of health from "the absence of disease or infirmity" to "the state of complete physical, mental, and social well-being", asset maps can help shift the culture of community health from that of assessing deficiencies to an approach that takes other factors into account as well. Through including other factors when addressing health, communities have "an opportunity to mobilize existing strengths and resources." (Kramer et al., 2012)In the long run, this ability can help "build social capital to catalyze change" (Baker et al., 2007) to improve overall community and population health.

The steps outlined in this article are adapted from the UCLA Centre for Health Policy and Research's guideline for creating an Asset Map (UCLA Centre for Health Policy Research, 2018). This was chosen as a guide because of UCLA's well-respected Public Health Program and the simplicity and pragmatism with which this guide is presented. This paper will assist readers in discovering why and how an asset map can be valuable to projects and communities, identifying examples of the assets to be mapped and who will be mapping them, presenting a step-by-step process guide, and lastly applying the guide to construct an asset map.

\subsection{Examples of Asset Mapping in Health and Wellness}

A methodological concept can be better understood when examples of it being applied in different contexts (Cutts et al., 2016; South et al., 2017) are shown. For this reason, this section provides a quick overview of three different areas where asset maps have proven

BRF Www.jBiomedAnalytics.org 
useful: health research, community engagement, and community partnerships. This is followed by a more in-depth look at a possible asset map compilation of health-related services available for the refugee population in Calgary.

\section{Health Research}

Public health can be addressed in a variety of ways through asset maps. One example (Smith et al., 2017), was a study that looked at the correlation of EMS [Emergency Medical Services] calls related to falls with the delivery of fall prevention-programming in Tarrant County, Texas, USA. The study looked at this relationship by comparing the prevalence and geospatial distribution of the two occurrences.

Another example is an asset map of Canadian clinical practice guidelines developed by The Strategy for Patient-Oriented Research [SPOR] Evidence Alliance, which is a Canada-wide alliance of researchers, healthcare providers, patients, policy makers, and knowledge users. The asset map included provincial, national and local clinical practice guidelines with the aim to provide opportunity to reduce redundancies and create the platform for further collaboration across different levels of stakeholders (SPOR, 2018).

\section{Community Engagement}

Organizations and institutions can also use asset maps to assess and increase the engagement of the communities in which they operate. A study that identified the underlying values that connected certain organizations in their ability to increase access to food and safe places to be active did so by assessing asset mapping workshops that asked community members to identify exemplary organizations that had a beneficial impact on access to food and safe places to be active (Jakes et al., 2015).

A second paper discussed the experience of Halifax Public Libraries in utilizing asset maps to better engage with the immigrant community in Halifax (Williment and Jones-Grant, 2012). Upon realizing that service providers were a valuable resource to better understand the immigrant community, an asset list was created of the various providers that served the immigrant community, and an effort was made to create relationships with each resource.

\section{Community Partnerships}

Partnerships can also be created through the use of asset maps by identifying potential partners. One example of this is seen in a study that used the partnerships created through asset maps to develop activities that served as alternatives to television viewing as part of an initiative to address childhood obesity (Baker et al., 2007).

Another paper discussed the experiences of a cohort of early intervention/early childhood special education [EI/ECSE] professionals that were able to realize the resources and learning opportunities that existed within their communities, to assist in their work with children with disabilities (Ordoñez-Jasis and Myck-Wayne, 2012). 


\section{Steps for doing an asset map}

Figure 1 provides a bird's eye view of the entire process of asset mapping. Each of the steps outlined in this figure will be expanded on in the next few paragraphs, but steps 1 to 6 can be summarized as such: why is the asset map being done?, where/which location[s] will the asset map assess?, who will be included in the execution of the asset map?, what types of assets will be included,? compiling the list of assets, and mapping the list of assets. The first five steps are always included, whereas the sixth and final step is optional, based on the purpose and receiving audience of the asset map. Just to make the point is the steps involved are very flexible and the following are simply guidelines to keep in mind, not concrete steps.

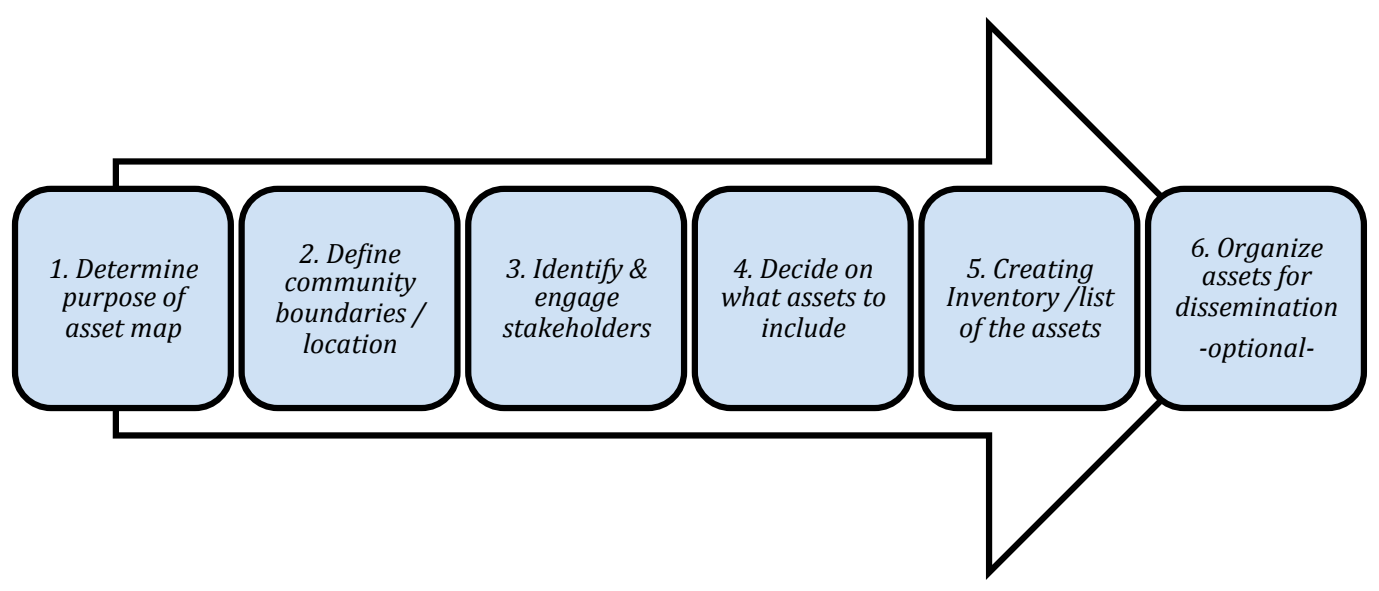

Figure 1: Bird's eye view of the asset map creation process.

\section{Step 1: Determine the purpose}

Having a clear idea of the purpose of any project makes it easier to not only develop a plan for the project, but execute the project as well. Three steps that can help clarify the purpose of the asset map are: coming up with questions that identify what you are looking to answer, further developing these questions through brainstorming sessions with a team, and then finalizing these questions [as shown in figure 2]. For example, an asset map was done (Baker et al., 2007) to identify assets that could be partnered with to decrease television viewing. The overall purpose of this initiative was to decrease childhood obesity, and since this was clearly understood and communicated by the authors, it allowed for a streamlined approach where partnerships weren't simply based on reducing television viewing, but rather on replacing television viewing with healthier activities. 


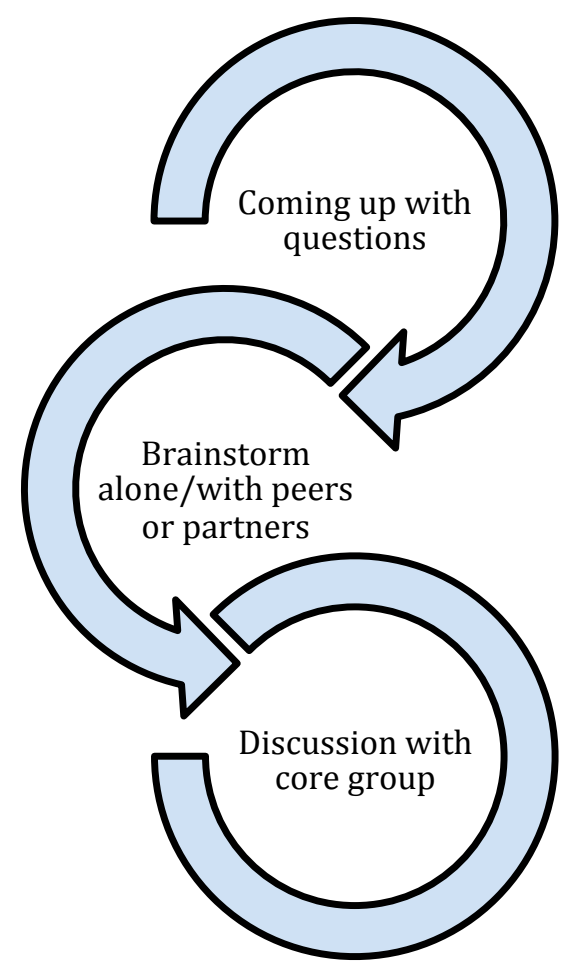

Figure 2: Define purpose.

\section{Step 2: Define community boundaries / location}

The second step in creating an asset map involves defining the geographical location that is being assessed. This needs to be done early in the process to help focus on the remainder of the steps. Finding relevant people [described in more details in step 3], for example, is much easier when a defined area has already been discussed. The importance of being explicit in this step cannot be emphasized enough- simply stating the neighbourhood's name may not be adequate; the more details provided, the better. Details [as seen in Figure 3] can include perceptions of that community's citizens, landmarks and other points of interest, as well as street names, to name a few. 


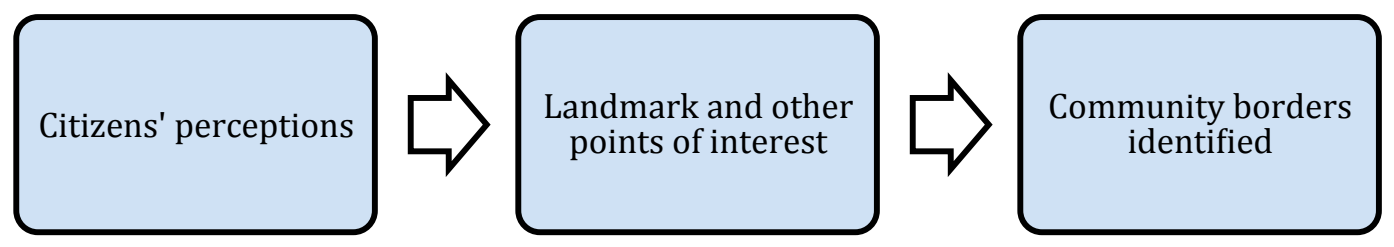

Figure 3: Define community boundaries.

\section{Step 3: Identify and engage stakeholders}

The next step in the process involves the recruitment of various groups of people to assist with the identification of assets within the boundary identified in the previous step. Figure 4 outlines some possible avenues to explore- people with a shared interest in the purpose of your asset map, people actively involved in pursuing similar objectives, experts in the field of interest, and organizations that can assist either through provision or subsequent support in identifying assets. This differs from the actual compilation of assets because this step focuses on people that are involved with the issue at hand and less with those who are assets within themselves, although some overlap may occur.

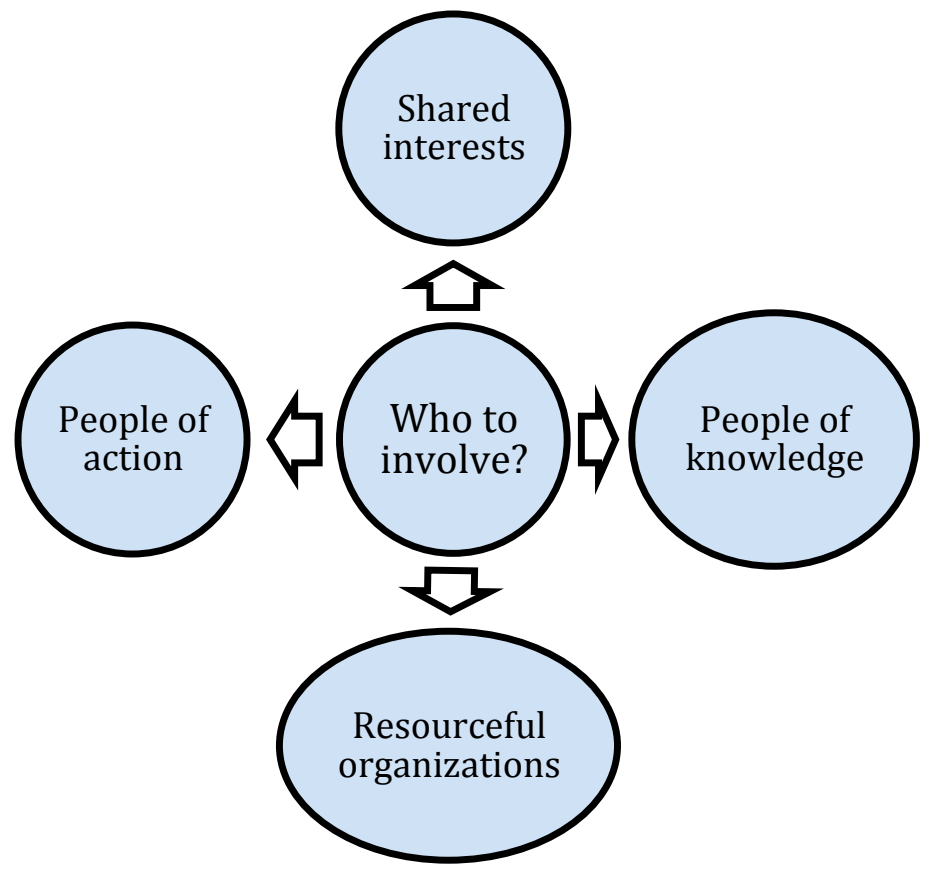

Figure 4: Identify \& engage stakeholders.

BRF www.jBiomedAnalytics.org 


\section{Step 4: Decide on what assets to Include}

The classical assets mentioned in the introduction and depicted in Figure 5 highlight different categories that can be explored for the identification of assets. This step helps to identify what types of assets are of interest, based on the purpose of the asset map. For example, if the purpose of the asset map is to identify ways for public libraries to better serve immigrants, then special focus can be made to identify other neighbourhood institutions [such as service providers] and local associations that regularly service the immigrant community (Baker et al., 2007). By understanding the importance of focusing on certain types of assets, more time and resources can be directed towards more fruitful asset types. Three different methods that can be used to focus on specific types of assets include the storytelling, heritage and whole assets approaches (Guy T, 2002), among others (Kramer et al., 2012).

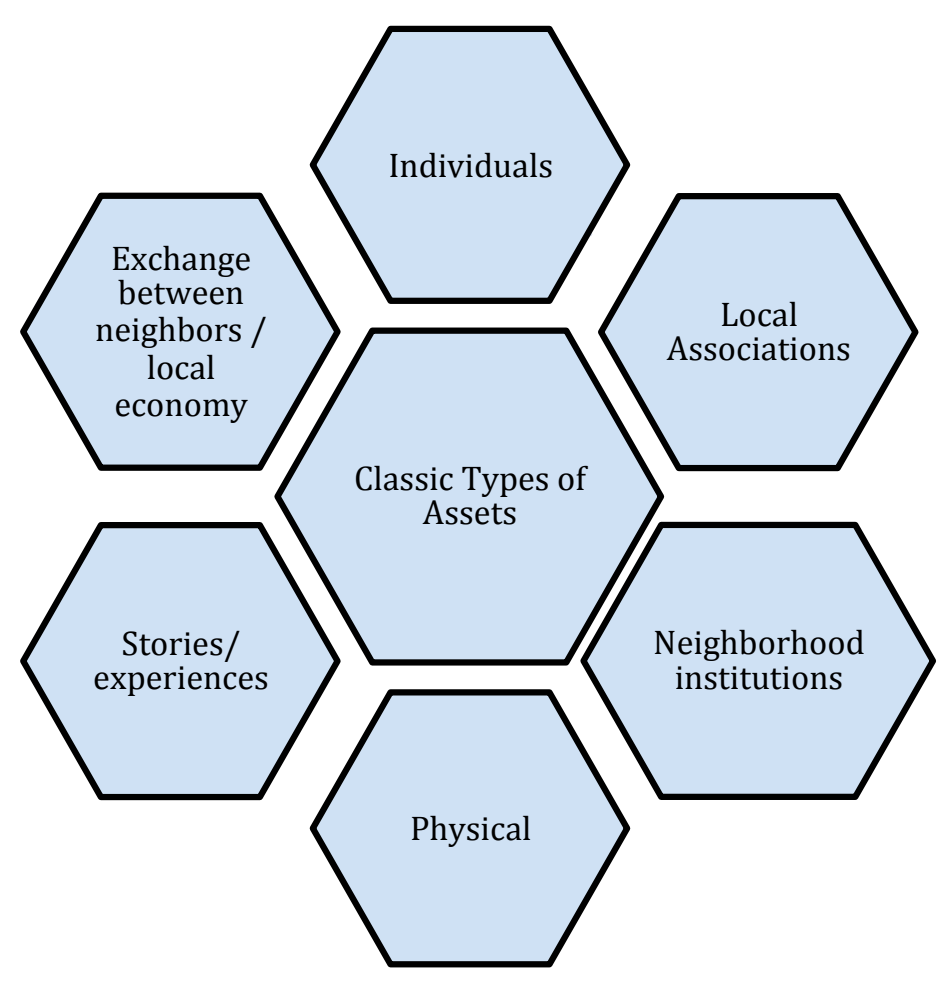

Figure 5: Decide what assets to include.

\section{Step 5: Asset information compilation}

The compilation of a list of relevant assets, while keeping all the previous steps in mind, is the most resource-consuming step since this requires exploration into the community of interest, whereas most of the other steps could be done through meetings and discussions. Thus, the step most associated with conducting an asset map is step 5, as seen in Figure 6: using the resources and feedback from partners' identified in step 3, detailed descriptions 
can be created about existing community assets, which are then compiled into an asset list for the community.

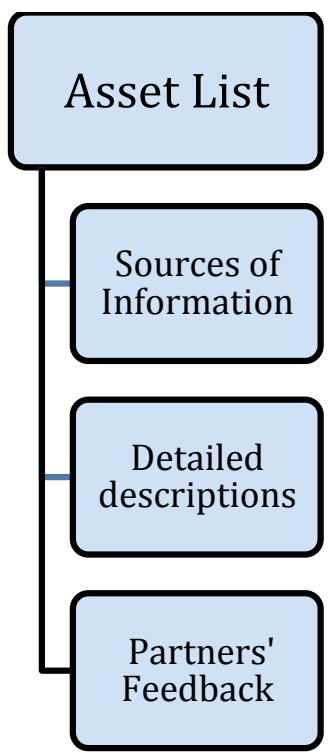

Figure 6: Compile / list assets.

\section{Step 6: Organize assets for dissemination}

As mentioned earlier, the inclusion of this final step depends on the purpose of the asset map, and whether the creation of a visual map of the asset list will benefit that purpose. The most basic method of mapping involves printing a geographical map of the area of interest and then highlighting the locations of the assets on the map through pins, dot stickers, etc. A few more specific and nuanced methods of creating visuals of asset maps can be seen in Figure 7, and are discussed elsewhere (Pánek, 2015).

?RF WWw.jBiomedAnalytics.org 


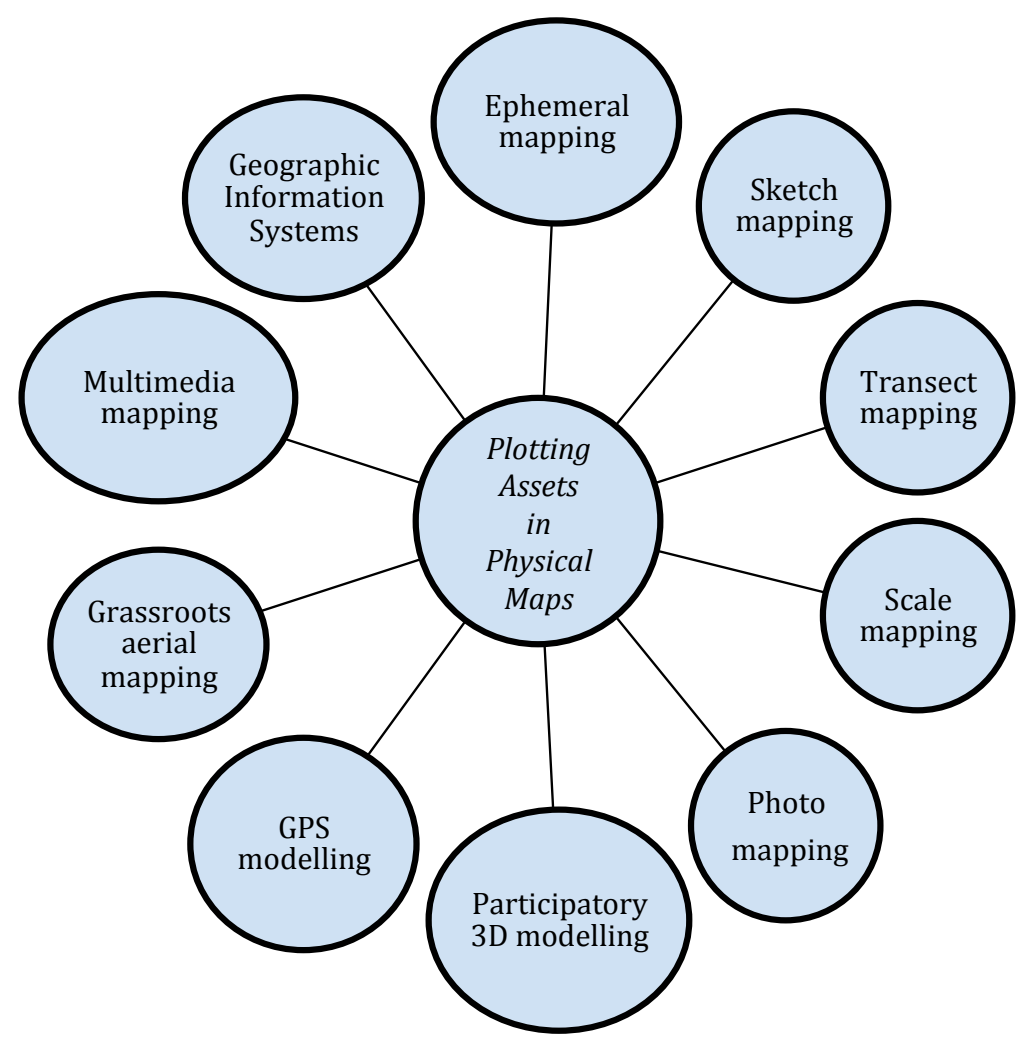

Figure 7: Different approaches of presenting the identified assets on physical maps for dissemination.

\section{A note to remember}

A unique and important characteristic to remember about asset maps is their flexibility. The steps presented above are guidelines that should be kept in mind when starting an asset map but should not become barriers to adapting the process to better address the purpose of the project.

\section{Working example: Asset map for health-related services for refugees in Calgary}

Calgary, having accepted over 6000 refugees between January 2015 and August 2018 (Monthly IRCC Updates, 2017), is one of the cities working towards more effective means of providing health services to a growing and unique population of refugees. Refugees coming into Canada often have difficulty navigating the public healthcare system (McKeary and Newbold, 2010), further worsening their already poor health outcomes. One of the methods through which this health inequity can be worked upon is through the construction of an 
asset map to assist in identifying the service locations that are providing positive and helpful health-related services [Step 1: Determine the Purpose].

This asset map can then be used to redirect refugees seeking help at other health-related services towards the assets/service centers identified, for the best possible care. The physical location that this asset map will cover is the City of Calgary [Step 2: Define Community Boundaries / Location].

Stakeholders of interest include people or organizations that have an interest or are in constant contact with refugee populations, such as Alberta Health Services, Alberta's Ministry of Health, Alberta's Ministry for Human Services, the City of Calgary Mayor's office, community leaders / champions working with non-governmental organizations dedicated towards refugee resettlement, community associations, etc. [Step 3: Identify and Engage Stakeholders].

The types of assets that we would be interested in compiling include hospitals, clinics, dentists, community health centers, pharmacies, to name some of the places where people may seek health services [Step 4: Define the Asset Types].

The information on assets will be compiled through comprehensive environmental scan which will include comprehensive internet and documentation scan as well as collecting information from all the stakeholders [Step 5: Asset Information Compilation].

Lastly, after working through the compilation of assets, the decision can be made to create pamphlets outlining the services available in each quadrant in Calgary and distributing them to areas and organizations that are known to be in constant contact with refugee populations [Step 6: Creating the Map].

A logic model was further created to describe this asset map creation process through a visual representation [Figure 8].

BRF www.jBiomedAnalytics.org 


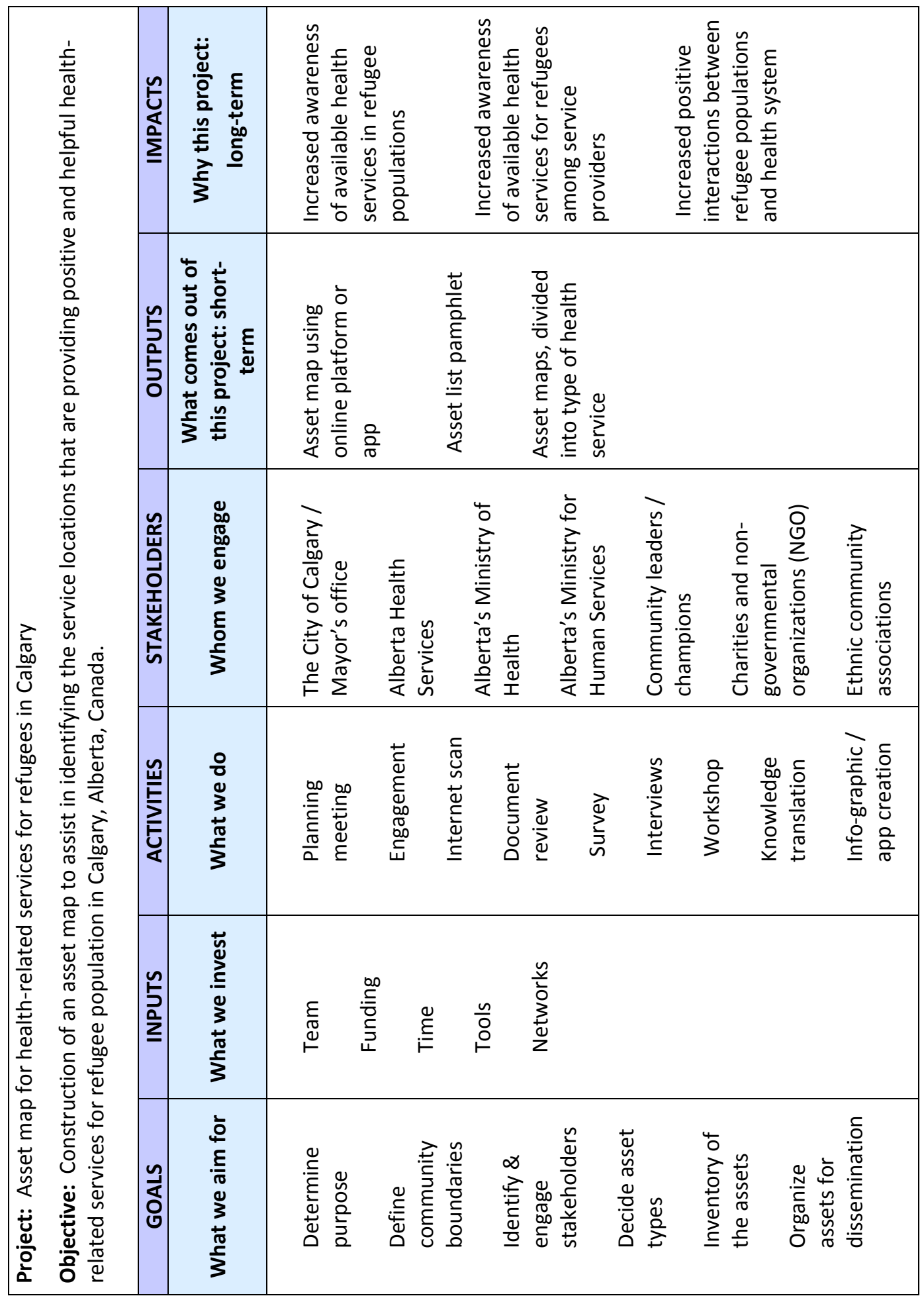

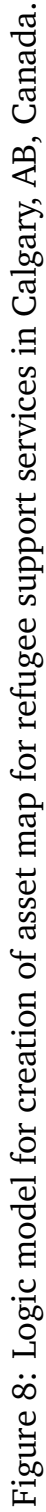

J Biomed Analytics, Vol. 2 No. 1 (2019), pp. 13-25 


\section{Conclusion}

The rapid increase in the use of asset maps as part of a toolbox to assess different situations and environments speaks to their usefulness, especially where service delivery is the focus. Overall, asset maps provide service providers, policy makers, researchers, community leaders and citizens a unique method to help assess the areas related to relevant issues and identify the strengths that are often overlooked by other approaches. Asset maps can also lead to reduced dependence and more efficient usage of external aid, along with the highlighting of opportunities to create community partnerships with newfound community assets.

\section{Declarations}

Funding: None.

Conflict of interest: The authors declare that they have no conflict of interests.

Ethical approval: Not applicable.

\section{References}

Baker IR, Dennison BA, Boyer PS, Sellers KF, Russo TJ, Sherwood NA (2007). "An assetbased community initiative to reduce television viewing in New York state." Preventive medicine, 44(5), 437-441.

Cutts T, Langdon S, Meza FR, Hochwalt B, Pichardo-Geisinger R, Sowell B, Chapman J, Dorton LB, Kennett B, Jones MT (2016). "Community health asset mapping partnership engages Hispanic/Latino health seekers and providers." North Carolina medical journal, 77(3), 160-167.

Guy T (2002). "Asset mapping: A handbook. Ottawa, Ontario: Canadian Rural Partnership." https://ccednet-rcdec.ca/en/toolbox/asset-mapping-handbook.

Jakes S, Hardison-Moody A, Bowen S, Blevins J (2015). "Engaging community change: the critical role of values in asset mapping." Community Development, 46(4), 392-406.

Kramer S, Amos T, Lazarus S, Seedat M (2012). "The philosophical assumptions, utility and challenges of asset mapping approaches to community engagement." Journal of Psychology in Africa, 22(4), 537-544.

Lightfoot E, McCleary JS, Lum T (2014). "Asset mapping as a research tool for communitybased participatory research in social work." Social Work Research, 38(1), 59-64.

McKeary M, Newbold B (2010). "Barriers to care: The challenges for Canadian refugees and their health care providers." Journal of Refugee Studies, 23(4), 523-545.

McKnight J, Kretzmann J (1993). "Building communities from the inside out: A path toward finding and mobilizing a community's assets."

BRF www.jBiomedAnalytics.org 
McKnight, J (2017). "Asset-Based Community Development [Internet]. Chicago, IL: AssetBased Community Development Institute." https://resources.depaul.edu/abcd-institute/ publications/publications-by-topic/Pages/default.aspx.

Monthly IRCC Updates (2017). "Canada - Admissions of Resettled Refugees by Province/Territory and Census Metropolitan Area (CMA) of Intended Destination and Immigration Category[Data File]." https://open.canada.ca/data/en/dataset/ 4a1b260a-7ac4-4985-80a0-603bfe4aec11.

Ordoñez-Jasis R, Myck-Wayne J (2012). "Community mapping in action: Uncovering resources and assets for young children and their families." Young Exceptional Children, 15(3), 31-45.

Pánek J (2015). "ARAMANI-decision-support tool for selecting optimal participatory mapping method." The Cartographic Journal, 52(2), 107-113.

Smith ML, Towne Jr SD, Motlagh AS, Smith DR, Boolani A, Horel SA, Ory MG (2017). "Programs and place: risk and asset mapping for fall prevention." Frontiers in public health, 5, 28.

South J, Giuntoli G, Kinsella K (2017). "Getting past the dual logic: findings from a pilot asset mapping exercise in Sheffield, UK." Health \& social care in the community, 25(1), 105-113.

SPOR (2018). "The Strategy for Patient-Oriented Research (SPOR) Evidence Alliance: Asset map of Canadian clinical practice guidelines." https://sporevidencealliance.ca/wp-content/uploads/2018/04/ SPOR-Evidence-Alliance_Asset-Map-of-Canadian-CPGs_Reportv3.pdf.

UCLA Centre for Health Policy Research (2018). "UCLA Centre for Health Policy Research. Section 1: Asset Mapping." http:/healthpolicy.ucla.edu/programs/health-data/trainings/ Documents/tw_cba20.pdf.

WHO (2018). "World Health Organization. Constitution of WHO: principles." http://www. who.int/about/mission/en/.

Williment KW, Jones-Grant T (2012). "Asset Mapping at Halifax Public Libraries: A Tool for Beginning to Discover the Library? Role with the Immigrant Community in Halifax." Partnership: The Canadian Journal of Library and Information Practice and Research, 7(1). 